\title{
Prevalence of Needlestick Injuries among Healthcare Workers in Rizgary Teaching Hospital
}

\author{
Salah H. Ali ${ }^{*}$, Peshtewan D. Majeed ${ }^{2}$, Umed A. Huwiezy ${ }^{3}$ \\ ${ }^{1}$ Department of Anesthesia, Erbil Medical Technical Institute, Erbil Polytechnic University, Erbil, Kurdistan Region, Iraq, ${ }^{2}$ Department of \\ Nursing, Erbil Medical Technical Institute, Erbil Polytechnic University, Erbil, Kurdistan Region, Iraq, ${ }^{3}$ Department of Pharmacy, Erbil Medical \\ Technical Institute, Erbil Polytechnic University, Erbil, Kurdistan Region, Iraq
}

\section{${ }^{*}$ Corresponding author: \\ Salah H. Ali, Department of Anesthesia, Erbil Medical \\ Technical Institute, Erbil Polytechnic University, Erbil, Kurdistan Region, Iraq. \\ E-mail: salah40hasan@ yahoo.com}

Received: 18 February 2020 Accepted: 19 May 2020

Published: 30 December 2020

DOI

10.25156/ptj.v10n2y2020.pp27-31

\section{A B S T R A C T}

Needlestick injury in healthcare settings is a global issue. Despite being recognized for many years, needlestick and sharps injuries (NSIs) continue to present a risk of occupational exposure to bloodborne pathogens for health care works (HCWs). The objectives of the study were to determine the prevalence of needlestick injuries among HCWs in Rizgary Teaching Hospital and to identify the causes of needlestick injuries. A cross-sectional study was conducted on 76 healthcare workers in Rizgary Teaching hospital; there were a total of 45 males, 31 females. The data collections were administrated using face-to-face interviews to ensure a good response rate and to ensure all questions were answered. Most $(52.6 \%)$ needlestick injuries occurred in wards with syringe needles being the most common causative tool; surgery ward was the most prevalent site of needlestick injuries occurrence $(42.1 \%)$. The percentage of acupuncture was high and needles were the most common cause, and most injuries occurred during the re-use of the needles. The study recommends several measures to prevent and reduce acute injuries among HCWs; these measures include health education, behavior change, safer devices, and an educational program to educate these HCWs.

Keywords: Erbil city; Healthcare workers; Needlestick injuries; Prevalence; Rizgary hospital

\section{INTRODUCTION}

Needlestick injuries still pose a high risk to healthcare workers (HCW) and a global concern for transmission of 20 blood-borne pathogens such as human immunodeficiency virus (HIV) and hepatitis B and C viruses (Goel et al., 2017; Morinaga et al., 2016). The National Monitoring System for Healthcare Workers identified any acupuncture injuries, percutaneous injury, needle penetration, or another sharp object that was in contact with blood, tissue, or other body fluids before exposure (Leigh et al., 2015). The Centers for Disease Control (CDC) of the USA estimated that exposure to blood and body fluids with sharp tools and needlestick and sharps injury (NSI) affects three million health workers annually with an estimated six million national security indicators each year (Lee et al., 2005). Therefore, the nurses are the first level of the staff whom contact with risk of infection from unsafe practices related to needles and sharps, and because they are amateurs, they lack experience and skill (Lachowicz and Mathews, 2009). Hence, the nurses are the commonest group of healthcare workers experiencing needlestick injuries, and although the prevalence of blood-borne pathogens in many developing countries is high, documentation of such exposures in these countries is negligible (O'Connor, 2009; Bekele et al., 2015)
Moreover, a lack of knowledge, access, or failure to use appropriate practice in the form of PPE contributes to an increased incidence of NSI among HCWs, and therefore factors such as hard work, fear of losing a job, and lack of knowledge about the needle the importance of stick injuries are the most important points not to report this, although reporting of acupuncture injuries is important for prevention and treatment (Ghanei et al., 2017), however, underreporting of acupuncture injuries in HCWs may be tenfold, therefore, health care authorities should not interpret a low prevalence rate as a lower infection in HCWs (Elder and Paterson, 2006). Some studies indicated that the prevalence of NSIs reached 68\% in Jordan (Khraisat et al., 2015), 74\% in South Korea (Cho et al., 2013), and 30\% in Turkey (Irmak, 2012). In another report, Jango noted that the majority (59.3\%) of $137 \mathrm{HCW}$ always recapped needle after use among those, the mean knowledge score was 3.8 (Janjua et al., 2007). In addition, In a study of Sadoh, almost a third of all respondents (31.9\%) admitted always recapping used needles (Sadoh et al., 2006); furthermore, according to Lee and Hassim's study, the prevalence of needlestick injuries among 285 Malaysian HCW was $24.6 \%$ involving 71 cases of which $48.0 \%$ were doctors, $22.4 \%$ were medical students, and $18.7 \%$ were nurses, and the difference was statistically significant (Lee and Hassim, 2005). Therefore, 
administering injection, withdrawing blood, recapping needles, disposing needles, and transferring blood or body fluid from syringe to specimen containers are common activities associated with sharp injuries (WHO, 2011). Therefore, HCWs who received the hepatitis B vaccine and who developed immunity to the virus are not at real risk, but the protection of $\mathrm{HCW}$ s through immunization (for HBV), use of protective equipment, and post-exposure management are important to prevent occupational hazards from exposure to and transmission of these blood-borne viruses (Deuffic-Burban et al., 2011).

\section{SUBJECTS AND METHODS}

This is a cross-sectional study carried out from February 2017 until March 2017 to determine the prevalence of needlestick injuries among HCWs. There were a total of 45 males and 31 females in Rizgary Teaching Hospital.

The survey research was carried out using a structured questionnaire. The questionnaires were divided into three parts. The first part consisted of questions on their sociodemographic characteristics. The other parts were on the prevalence study of needlestick injuries, where the respondents were asked about their experience in handling needles and the prevalence of needlestick injuries in the last year. For blood-borne diseases, the questions were about hepatitis B and standard precautions.

The data collections were administrated using face-to-face interviews to ensure a good response rate and to ensure all questions were answered. Needlestick injury in this study refers to percutaneous injury caused by a needle or sharp instrument. Prevalence of cases of needlestick injury is the total number of cases of needlestick injuries in 1 year (2016) divided by the total number of respondents and stated as a percentage. Prevalence of episode of needlestick injury is the total number of episodes of needlestick injuries in 1 year (2016) divided by total respondents in percentage. Data obtained were entered into an Excel spreadsheet and summarized using frequencies and percentages.

\section{RESULTS}

Seventy-six HCWs participated in the study. There were $59.2 \%$ males and $40.8 \%$ females. Most of the participants, $40.8 \%$ were in the $30-39$-year age range with a mean age of 24.82 , while a small fraction $9.2 \%$ were observed in the age group of 50 years and above. Most of the study samples were $81.6 \%$ hold the diploma certificate.

Out of the 76 cases of needlestick injury, $59(77.6 \%)$ of them wore gloves. The other 17 cases $(22.4 \%)$ did not wear gloves and gave reasons such as unnecessary because the patient was not a blood-borne pathogen carrier, not able to palpate the pulse, allergic to rubber gloves. The most important risk factor for needlestick injuries was lack of training on such injuries and other important risk factors, including recapping needles most of the time [Table 1].

Needles were the most common actions that resulted to NSIs $(52.6 \%)$ of all exposures. Surgery ward was the most prevalent site of NSIs occurrence $(42.1 \%)$ and other wards were internal ward $(26.3 \%)$, gynecology ward $(15.8 \%)$, laboratory $(9.2 \%)$, and emergency ward $(6.5 \%)$. Fifty-eight respondents $(76.3 \%)$ had been vaccinated against hepatitis $B$ and 32 were completed the vaccination schedule. Eighteen respondents were not vaccinated and

\begin{tabular}{|c|c|c|}
\hline Variable & $\begin{array}{c}\text { Frequency } \\
n=76\end{array}$ & $\%$ \\
\hline \multicolumn{3}{|l|}{ Age groups } \\
\hline 20-29 & 26 & 34.2 \\
\hline 30-39 & 31 & 40.8 \\
\hline $40-49$ & 12 & 15.8 \\
\hline $50 \geq$ & 7 & 9.2 \\
\hline \multicolumn{3}{|l|}{ Gender } \\
\hline Male & 45 & 59.2 \\
\hline Female & 31 & 40.8 \\
\hline \multicolumn{3}{|c|}{ Educational level } \\
\hline Diploma & 62 & 81.6 \\
\hline Bachelor & 14 & 18.4 \\
\hline \multicolumn{3}{|c|}{ Years of experiences } \\
\hline$\leq 5$ & 28 & 36.8 \\
\hline $6-10$ & 21 & 27.6 \\
\hline $11-15$ & 8 & 10.5 \\
\hline $16-20$ & 9 & 11.8 \\
\hline $21-25$ & 4 & 5.2 \\
\hline $26-30$ & 2 & 2.6 \\
\hline$\geq 30$ & 4 & 5.2 \\
\hline \multicolumn{3}{|c|}{ Do you use safety box? } \\
\hline No & 30 & 39.5 \\
\hline Yes & 46 & 60.5 \\
\hline \multicolumn{3}{|c|}{ Recapping/un recapping of needles } \\
\hline No & 12 & 15.8 \\
\hline Yes & 64 & 84.2 \\
\hline \multicolumn{3}{|c|}{ Do you have history with needlestick injuries } \\
\hline No & 15 & 19.7 \\
\hline Yes & 61 & 80.3 \\
\hline \multicolumn{3}{|c|}{ Using of latex gloves } \\
\hline No & 17 & 22.4 \\
\hline Yes & 59 & 77.6 \\
\hline \multicolumn{3}{|c|}{ Contaminated of exposed needles } \\
\hline No & 30 & 39.5 \\
\hline Yes & 46 & 60.5 \\
\hline \multicolumn{3}{|c|}{ Post-injury prophylaxis } \\
\hline No & 34 & 44.7 \\
\hline Yes & 42 & 55.3 \\
\hline
\end{tabular}


reasons given for non-vaccination were that they did not know their hepatitis B status or were busy and had not had time to go for vaccination. The percentage of respondents who routinely used safety containers for disposal of sharps and needles was $53.9 \%$. The reasons for those who did not report $(81.6 \%)$, because it is not the hospital policy/ rules' requiring all needlestick injuries to be reported, the incidence was not important, worried about future consequences if known by the administration, did who to report to, did not know injuries reportable [Table 2].

The most common activity leading to needlestick injuries was taking blood $48.7 \%$, recapping of needle $42.1 \%$, setting of drips $40.8 \%$, suturing $30.1 \%$, and parental injection $28.9 \%$ [Table 3].

\section{DISCUSSION}

Needlestick injuries are the most frequent occupational hazard affecting HCWs, and the most life threatening. Nursing are at high risk for NSIs because of their nature of work. This cross-sectional study involved that a total of 76 study subjects among them $62(81.6 \%)$ needlestick injuries were not reported.

In the present study found that the majority cases (42.1\%) of needle injuries were due to recapping the needles, this result is come with the studies; $36.6 \%$ in study of Mobasherizadeh et al., 2011, 21.57\% in study of Galougahi, 2010, and $15.2 \%$ in study conducted in Mongolia of Kakizaki et al., 2011, while in present study, the using safety boxes for disposal of contaminated needles in clinical wards and departments have been on the rise in recent years were $60.5 \%$, avoiding the recapping of contaminated needles is recommended to reduce the incidence of injuries (AdibHajbaghery and Lotfi, 2013).

The most important underlying causes of needle stick were, respectively, as recapping (42.1\%), IV time fixing (40.8\%), and injections $(28.9 \%)$. Identical to a study conducted by Shokuhi et al., it was shown that the cause of needle stick occurrence was as follows: Recapping: $26.5 \%$, suture: $24.7 \%$, and fixed IV: 24.4\% (Shokuhi et al., 2012). In Rakhshani et al. as well study conducted in Zahedan, the most important causes were blood sampling and injections (Rakhshani et al., 2009). In the current study, it seems that due to the high rate of recapping of needles in the hospitals. therefore, the safe injection instructions should be retrained. however, educational training was the main element in increasing the knowledge and improving behavior and performance the healthcare workers.

In the present study, the highest needlestick injuries were reported, respectively, in the surgery ward $(42.1 \%)$, internal
Table 2: Distribution of needlestick injuries status among the studied sample

\begin{tabular}{|c|c|c|}
\hline Variable & Frequency $n=76$ & $\%$ \\
\hline \multicolumn{3}{|l|}{ Ward of injury happening } \\
\hline Surgery & 32 & 42.1 \\
\hline Gynecology & 12 & 15.8 \\
\hline Internal & 20 & 26.3 \\
\hline Emergency & 5 & 6.5 \\
\hline Laboratory & 7 & 9.2 \\
\hline \multicolumn{3}{|c|}{ The action resulting in needlestick injuries } \\
\hline Due to negligence & 8 & 10.5 \\
\hline Movement of the patient & 14 & 18.4 \\
\hline Remove the cap & 14 & 18.4 \\
\hline Syringe needle & 40 & 52.6 \\
\hline \multicolumn{3}{|l|}{ Placing needle in container } \\
\hline No & 35 & 46.1 \\
\hline Yes & 41 & 53.9 \\
\hline \multicolumn{3}{|c|}{$\begin{array}{l}\text { Participation in a training course about preventive measurement of } \\
\text { needlestick injuries }\end{array}$} \\
\hline No & 30 & 39.5 \\
\hline Yes & 46 & 60.5 \\
\hline \multicolumn{3}{|c|}{ Use of protective equipment (face masks, waistcoats, and gloves) } \\
\hline No & 15 & 19.7 \\
\hline Yes & 61 & 80.3 \\
\hline \multicolumn{3}{|l|}{ Received hepatitis B vaccine } \\
\hline No & 18 & 23.7 \\
\hline Yes & 58 & 76.3 \\
\hline \multicolumn{3}{|c|}{ Have you completed the vaccination schedule? } \\
\hline No & 44 & 57.9 \\
\hline Yes & 32 & 42.1 \\
\hline \multicolumn{3}{|l|}{ Reporting or not reporting } \\
\hline No & 62 & 81.6 \\
\hline Yes & 14 & 18.4 \\
\hline
\end{tabular}

Table 3: Needle injuries according to procedures and stages of withdrawal blood

\begin{tabular}{lcc}
\hline Variable & Frequency $\mathbf{n = 7 6}$ & $\%$ \\
\hline Procedures & & \\
Withdrawal blood & 37 & 48.7 \\
Setting drip & 31 & 40.8 \\
Parenteral injections & 22 & 28.9 \\
$\quad$ Suturing & 23 & 30.1 \\
Stages of withdrawal blood & & \\
Removing needle cap & 10 & 13.2 \\
Recapping needle & 32 & 42.1 \\
Inserting needle into vein & 31 & 40.8 \\
Removing needle & 21 & 27.6 \\
\hline
\end{tabular}

medicine wards $(26.3 \%)$, and gynecology wards $(15.8 \%)$. While a study by Askarian et al. showed that $31.4 \%$ of all needlestick events have occurred in the maternity ward, while $22.9 \%$ and $17.9 \%$ have occurred in operating rooms and emergency rooms, respectively, (Askarian et al., 2012). The results of the present study showed that $76.3 \%$ of all subjects had been completely vaccinated against Hepatitis B.

In the present study, the proportion of HCWs who reported to authorities after NSIs was $18.4 \%$, and the main 
reason for not reporting was the patient's negative test, or some of them tended to self-assess rather than report such injuries. Hepatitis B vaccination of all at risk HCWs in the present study (23.7\% never received). It is recommended by the CDC that all at risk HCWs be vaccinated against HBV infection (CDC, 1997).

This study confirmed that syringe needles are the most common causative device as it accounted for $52.6 \%$ of all needlestick injury events. A similar percentage (72\%) was documented among HCWs in a tertiary hospital in Korea (Park et al., 2008) another study showed that syringe needles were responsible for as high as $92 \%$ of needlestick injury events among nurses (Phipps et al., 2002).

A study conducted in Singapore (Ng et al., 2002) indicated that syringe needles are responsible for about $23.2 \%$ among healthcare workers, compared to $52 \%$ among professional nurses in Korea, as well as in Australia (Smith et al., 2006). International research has yielded conflicting results with regard to circumstances surrounding needlestick injuries; for example, an American hospital study has shown that the highest needlestick injury rate occurred "after use and before disposal" (Smith et al., 2006). In the present study, $42.1 \%$ of needlestick injury events occurred while recapping a needle. Recapping needles is a high-risk activity regarding needlestick injury and the most common cause of needlestick injuries (Smith et al., 2006). In the USA, the recapping of needles has been prohibited under the Occupational Safety and Health Administration bloodborne pathogen standard (NIOSH, 2000).

\section{CONCLUSION}

Needlestick injuries are a significant occupational hazard for nurses. The percentage of acupuncture was high and needles were the most common cause and most injuries occurred during the re-use of the needles.

\section{Recommendations}

The study recommends several measures to prevent and reduce acute injuries among $\mathrm{HCW}$. These measures include health education, behavior change, safer devices, and an educational program to educate these HCWs.

\section{REFERENCES}

Adib-Hajbaghery M and M. S. Lotfi. 2013. Behavior of healthcare workers after injuries from sharp instruments. Trauma Mon. 18: 75-80.

Askarian, M., L. Malekmakan, Z. A. Memish and O. Assadian. 2012. Prevalence of needle stick injuries among dental, nursing and midwifery students in Shiraz, Iran. GMS Krankenhhyg Interdiszip. 7: Doc05.
Bekele, T., A. Gebremariam, M. Kaso and K. Ahmed. 2015. Attitude, reporting behaviour and management practice of occupational needle stick and sharps injuries among hospital healthcare workers in Bale zone, Southeast Ethiopia: A crosssectional study. J. Occup. Med. Toxicol. 10: 42.

Centers for Disease Control and Prevention. 1997. Immunization of health care workers. MMWR. 46: 1-42.

Cho, E., H. Lee, M. Choi, S. H. Park, I. Y. Yoo and L. H. Aiken, 2013. Factors associated with needlestick and sharp injuries among hospital nurses: A cross-sectional questionnaire survey. Int. J. Nurs. Stud. 50: 1025-1032.

Deuffic-Burban, S., E. Delarocque-Astagneau, D. Abiteboul, E. Bouvet and Y. Yazdanpanah. 2011. Blood-borne viruses in health care workers: Prevention and management. J. Clin. Virol. 52: 4-10.

Elder, A. and C. Paterson. 2006. Sharps injuries in UK health care: A review of injury rates, viral transmission and potential efficacy of safety devices. Occup. Med. 56: 566-574.

Galougahi, M. H. 2010. Evaluation of needle sticks injuries among nurses of Khanevadeh Hospital in Tehran. Iran. J. Nurs. Midwifery Res., 15: 172-7.

Gheshlagh, R. G., M. Nazari, V. Baghi, S. Dalvand, A. Dalvandi and K. Sayehmiri. 2017. Underreporting of needlestick injuries among healthcare providers in Iran: A systematic review and metaanalysis. J. Hayat. 23: 201-213.

Goel, V., D. Kumar, R. Lingaiah and S. Singh. 2017. Occurrence of needlestick and injuries among healthcare workers of a tertiary care teaching hospital in North India. J. Lab. Physicians. 9: 20-25.

Irmak, Z. 2012. Needlestick and sharps injury among nurses at a state hospital in Turkey. Aust. J. Adv. Nurs., 30: 48-55.

Janjua, N. Z., M. Razaq, S. Chandir, S. Rozi and B. Mahmood. 2007. Poor knowledge--predictor of nonadherence to universal precautions for blood borne pathogens at first level care facilities in Pakistan. BMC Infect. Dis. 7: 81.

Kakizaki, M., N. Ikeda, M. Ali, B. Enkhtuya, M. Tsolmon, K. Shibuya and C. Kuroiwa. 2011. Needle stick and sharps injuries among health care workers at public tertiary hospital's Trauma Mon. In an urban community in Mongolia. BMC Res. Notes. 4: 184.

Khraisat, F. S., M. H. Juni, M. Salmiah, A. A. Rahman and A. HamdanMansour. 2015. Needle-stick injuries prevalence among nurses in Jordanian hospitals. Int. J. Public Health Clin. Sci. 2: 7-16.

Lachowicz, R. and P. Mathews. 2009. The pattern of sharps injury to health care workers at Witbank Hospital. South Afr. Fam. Pract. 51: 148-151.

Lee, J. M., M. F. Botteman, N. Xanthakos and L. Nicklasson. 2005. Needlestick injuries in the United States. Epidemiologic, economic, and quality of life issues. AAOHN J. 53: 117-133.

Lee, L. K. and I. N. Hassim. 2005. Implication of the prevalence of needle sticks injuries in a general hospital in Malaysia and its risk in clinical practice. Environ. Health Prev. Med. 10: 33-41.

Leigh, J.P., C. A. Markis, A. M. Iosif and P. S. Romano. 2015. California'snurse-to-patient ratio law and occupational injury. Int. Arch. Occup. Environ. Health, 88: 477-484.

Mobasherizadeh, S., A. Ebneshahidi, M. Rahimi, M. Ostadrahimi and G. R. Masoumi. 2011. Needle-stick injuries in Isfahan, Iran: Quality improvement. BMC Proc. 5: 221.

Morinaga, K., K. Hagita, T. Yakushiji, H. Ohata, K. Sueishi and T. Inoue. 2016. Analysis of needlestick and similar injuries over 10 years from April 2004 at Tokyo dental college Chiba hospital. Bull. Tokyo Dent. Coll. 57: 299-305.

National Institute for Occupational Safety and Health. 1999. Preventing Needle Stick Injuries in Health Care Settings. DHHS (NIOSH) Publication No. 2000-108. 
Ng, L. N., H. L. Lim, Y. H. Chan and D. Bin Bachok. 2002. Analysis of sharps injury occurrences at a hospital in Singapore. Int. J. Nurs. Pract. 8: 274-281.

O'Connor, M.B. 2009. Needle sticks injury advices in the UK and Ireland. J. Hosp. Infect. 71: 185-186.

Park, S., I. Jeong, J. Huh, Y. Yoon, S. Lee and C. Choi. 2008. Needlestick and sharps injuries in a tertiary hospital in the Republic of Korea. Am. J. Infect. Control. 36: 439-443.

Phipps, W., W. Honghong, Y. Min, J. Burges, L. Pellico, C. Watkins and H. Guoping. 2002. Risk of medical sharps injuries among Chinese nurses. Am. J. Infect. Control. 30: 277-282.

Rakhshani, F., M. Heidari and S. Barati. 2009. Prevalence of needle stick Injuries among the healthcare professionals in Zahedan medical sciences university. Iran. J. Epidemiol. 4: 87-91.
Sadoh, W. E., A. O. Fawole, A. E. Sadoh, A. O. Oladimeji and O. S. Sotiloye. 2006. Practice of universal precautions among healthcare workers. J. Natl. Med. Assoc. 98: 722-726.

Shokuhi, S., L. Gachkar, I. Alavi-Darazam, P. Yuhanaee and M. Sajadi. 2012. Occupational exposure to blood and body fluids among health care workers in teaching hospitals in Tehran, Iran. Iran. Red. Crescent Med. J. 14: 402-407.

Smith, D. R., M. A. Choe, J. S. Jeong, M. Y. Jeon, Y. R. Chae and G. J. An. 2006. Epidemiology of needle sticks and sharps injuries among professional Korean nurses. J. Prof. Nurs. 22: 359-366.

Smith, D. R., W. Smyth, P. A. Leggat and R. S. Wang. 2006. Needle sticks and sharps injuries among nurses in a tropical Australian hospital. Int. J. Nurs. Pract. 12: 71-77.

World Health Organization. 2011. HIVIAIDS on Work Place. 